\title{
The life outcomes of children during COVID-19: Exploring the protective roles of the joint and nuclear families in India
}

Gyanesh Kumar Tiwari ${ }^{1}$, Raghavendra Prasad Tiwari ${ }^{2}$, Rakesh Pandey ${ }^{3}$, Dr. Bablu Ray ${ }^{4}$, Abhigyan Dwivedi ${ }^{5}$, Devaki Nandan Sharma ${ }^{6}$, Pankaj Singh ${ }^{7}$, and Ajay Kumar Tiwari ${ }^{8}$

${ }^{1}$ Affiliation not available

${ }^{2}$ Vice-Chancellor, Doctor Harisingh Gour Vishwavidyalaya, Sagar, 470003, Madhya

Pradesh, India, Email: mzurpt@gmail.com

${ }^{3}$ Department of Psychology, Faculty of Social Sciences, Banaras Hindu University,

Varanasi, 221005, Uttar Pradesh, India, Email: rpandeybhu@gmail.com

${ }^{4}$ Department of Linguistics, School of Languages, Doctor Harisingh Gour Vishwavidyalaya, Sagar, 470003, Madhya Pradesh, India, Email: babluray@gmail.com

${ }^{5}$ Department of Linguistics, School of Languages, Doctor Harisingh Gour Vishwavidyalaya, Sagar, 470003, Madhya Pradesh, India, Email: abhigyan5983@gmail.com

${ }^{6}$ Department of Psychology, School of Humanities \& Social Sciences, Doctor Harisingh

Gour Vishwavidyalaya, Sagar, 470003, Madhya Pradesh, India Email:

devesh1110@gmail.com

${ }^{7}$ Department of History, School of Humanities \& Social Sciences, Doctor Harisingh Gour

Vishwavidyalaya, Sagar, 470003, Madhya Pradesh, India, Email:

drpankajsingh77@gmail.com

${ }^{8}$ Naisubah Institute of Mental Health and Behavioral Sciences, Varanasi, Uttar Pradesh, India, Email: ajay.naisubah@gmail.com

August 17, 2020

\begin{abstract}
Using a qualitative approach, we explored the protective roles of joint and nuclear families in shaping the life outcomes of children during COVID-19. Sixteen full-time mothers of children aged 9-12 years (8 each from joint and nuclear families) were interviewed and thematic analysis revealed five major themes viz., negative impacts, differences in positive engagement, emotional protective roles, promotion of positive health habits and activity management. Findings suggest that joint families carry more resources to positively engage their children in creativity, studies, exercise and entertainment as compared to nuclear families. Contrary to nuclear families, joint families gave emphasis to resolve emotional grievances, promote positive emotional engagement and support emotionally. The joint and nuclear families also differed in attending food habits, health grievances and physical exercise of children. The joint families played more positive roles in managing play behaviours, sleep habits, television watching and other activities of children compared to nuclear families.
\end{abstract}

Keywords: children; COVID-19; joint family; life outcomes; nuclear family; thematic analysis.

\section{Introduction}

The COVID-19 pandemic has caused significant influences on the lives of people of all age groups around the globe. Its seriousness can be understood in terms of the worldwide infected $(17,106,007)$ and death $(668$, 
910) cases of COVID-19 by July 31, 2020 (World Health Organization, 2020). Due to the unprecedented and unparallel restrictions, fear and uncertainty, COVID-19 has created an indescribable situation of anguish and pain in the whole of humanity. It has created severe mass distress, anxiety, uncertainty, panic and challenges to the life outcomes of children and adults (Jiao et al., 2020; Tiwari, Singh, et al., 2020). United Nations Organization (2020) has observed that children are one of the biggest sufferers of this pandemic and its negative influences may be significantly shaped by the economic and social conditions of families and their health conditions. Children are facing acute availability to the needed resources, social support and services which may lead them to bear the pain of psychological distress, violence, abuse, neglect and exploitation which, in turn, may badly affect their development and well-being (Avenue et al., 2020; Lee, 2020). These negative consequences for children may go beyond imagination since the current pandemic is more traumatic, pervasive and uncertain (Galea et al., 2020; Tiwari, Pandey, et al., 2020; Tiwari, Rai, et al., 2020).

The family acts as an important and universal agency which provides care for children. Various forms of families with different structures and functions are found. One typology is a joint family and the nuclear family. According to Merriam-Webster Dictionary (2020a), a joint family is a consanguineal unit that includes two or more generations of kindred related through either paternal or maternal line who maintain a common residence and are subject to common social, economic and religious regulations. A nuclear family is defined as a group that consists only of parents and children (Merriam-Webster Dictionary, 2020b). The joint family system is the major vehicle of collective values which are guided by shared identity, deep attachments, unique socialization, emotionality, meaning, relationships, concern for others, interdependence and relatively permanent relationships (Cai et al., 2013; Gaines et al., 1997; Hoshino-Browne et al., 2005; Scabini \& Manzi, 2010). Parallel to this, a nuclear family is based on individualistic values and lays emphasis on individual identity, independence, self-esteem and personal achievements (Cai et al., 2013; Gupta \& Sukamto, 2020; Markus \& Kitayama, 1991).

Dissimilar life outcomes have been linked with the two-family systems. For example, a joint family is more supportive for children to achieve psychological well-being than a nuclear family (Gul et al., 2017). The differences in the outcomes of children of the two family systems have been assumed to be the results of dissimilarities in parent relations and social relations (Bernardi et al., 2013; Mackay, 2005), kin rivalry (Kreppner, 2013) and parental resources, the mental health of parents, parent-child relations, quality of relationships between parents and parental discrepancy (Fomby \& Cherlin, 2007; Y. Sun \& Li, 2002). A study has shown that the children of joint families show better performance on the various components of psychological well-being such as autonomy, environmental mastery, personal growth, positive relations, purpose in life and self-acceptance as compared to their nuclear family counterparts (Gul et al., 2017). Children from joint families show lower behavioural problems (Kauts \& Kaur, 2016) and higher emotional maturity (Kondiba \& Hari, 2018).

There is an explicit gap in the literature as previous studies on children have been limited to less severe natural or man-made adversities on the life outcomes of children (Klein et al., 2009; Lee, 2020; United Nations Organization, 2020). It has been argued that the psychological impacts of COVID-19 for the general population has been well-documented and there is a lack of studies involving parents, families and children (Brooks et al., 2020; Jiao et al., 2020). The distress of the current pandemic has severely influenced the life outcome of children similar to adults (Wang et al., 2020). The study of children is also important for other reasons. Families differ in providing care and support to their children. For example, a joint family may provide more live, long-term and varied positive stimulations emanating from the dynamics of relationships among children, siblings, parents, grandparents and other relatives. On the other hand, a nuclear family may become naturally restrictive and less live and short-term stimulating due to the limited size and variety of relationships.

The unprecedented challenges created by the current pandemic may have exerted its impacts on the functioning of different family systems and individuals including children in a novel, severe and less-known manner. It compelled the authors to choose a qualitative research design for capturing the roles of joint and nu- 
clear families in providing protections to their children from the ill-consequences of COVID-19. Qualitative methods have been recommended to be useful in situations where there is no guiding framework, theory, measures and the phenomenon is novel (Creswell, 2014). Due to the nationwide restrictions of lockdown and quarantine in India to prevent further spreading of COVID-19, the basic and detailed information regarding the behaviours and experiences of children were not possible to measure. Thus, parents, especially full-time mothers remain the chief source of data regarding their children. A full-time mother was the incessant primary caregiver from birth to the present (Ahirwar et al., 2019). In some previous studies, collecting data from the parents, especially full-time mothers of younger children have been reported to be useful (Ahirwar et al., 2019; Tiwari, Singh, et al., 2020). The current study chose children between 9 years to 12 years. This age group was chosen since the children of this age group remain dependent on their parents and other family members for their satisfaction of needs and care to some extent. Besides, these children are able to speak out their demands, show understandable emotional and behavioural responses. This makes their behaviour comprehensive, stable and patterned. Besides, these children also understand the necessity and compulsion of the adherence to the restrictions of the lockdown. It has been suggested that the children of this age group develop some sense of life goals, able to share their positive and negative experiences with their caregivers and reflect some understanding of life realities and broader human collectives (Tiwari, Singh, et al., 2020). In this backdrop, the present study aims to explore the protective roles of joint and nuclear families in shaping the life outcomes of children with age ranging between 9 years to 12 years during the restrictions of COVID-19 through a qualitative research design. The telephonic mode of data collection was adopted since face-to-face interaction was restricted due to restrictions of lockdown.

\section{Methods}

\section{Research Design}

The current study employed a qualitative research design. The data were collected through a telephonic semistructured interview protocol to come up with a deeper understanding of the full-time mothers' descriptions and experiences of the happenings and restrictions of the pandemic, and the role of two-family systems regarding their children. The study used a constructivist approach which refers to a dialogical exchange between the interviewers and interviewees to the experiences and meanings held by them (Levitt et al., 2017, 2018).

\section{Participants}

Initially, 27 full-time mothers from 15 joint and 12 nuclear families were contacted on their phones through a snowball technique and asked to take part in the study. Out of these, only 16 mothers with the age range between 33 years to 45 years gave their telephonic consent. Eight mothers were from joint families (Mean Age $=41.63, \mathrm{SD}=2.62$ ) and the rest 8 were from nuclear families (Mean Age $=37.50, \mathrm{SD}=3.07$ ). The age range of their children was 9 years to 12 years (Mean Age $=10.66, \mathrm{SD}=1.17$ ). The sample was selected from the Indian cities such as Sagar, New Delhi, Varanasi and Lucknow (See Table 1). 
Table 1

Demographic Features of the Mothers and Their Children

\begin{tabular}{|c|c|c|c|c|c|c|c|c|c|c|}
\hline \multirow[b]{2}{*}{ S. No. } & \multirow[b]{2}{*}{ Codes } & \multicolumn{5}{|c|}{ Full-time Mothers } & \multicolumn{3}{|c|}{ Children } & \multirow[b]{2}{*}{$\begin{array}{l}\text { Length of } \\
\text { interview }\end{array}$} \\
\hline & & Age & Education & Family & Members & Domicile & Gender & $\begin{array}{l}\text { Age } \\
\text { (yrs.) }\end{array}$ & Class & \\
\hline 1. & N_F_1 & 35 & Graduate & Nuclear & 04 & Urban & Female & 09 & $2^{\text {nd }}$ & 71 \\
\hline 2. & N_M_1 & 33 & Postgraduate & Nuclear & 03 & Urban & Male & 09 & $2^{\text {nd }}$ & 73 \\
\hline 3. & J_M_2 & 40 & Graduate & Joint & 10 & Urban & Male & 12 & $8^{\text {th }}$ & 65 \\
\hline 4. & J_F_2 & 45 & Graduate & Joint & 10 & Urban & Female & 11.50 & $8^{\text {th }}$ & 60 \\
\hline 5. & J_F_3 & 41 & Graduate & Joint & 06 & Urban & Female & 10 & $7^{\text {th }}$ & 63 \\
\hline 6. & J_M_3 & 39 & $12^{\text {th }}$ & Joint & 16 & Urban & Male & 11 & $7^{\text {th }}$ & 81 \\
\hline 7. & J_F_4 & 38 & $\mathrm{Ph} . \mathrm{D}$. & Joint & 06 & Urban & Female & 11 & $7^{\text {th }}$ & 60 \\
\hline 8. & N_M_4 & 35 & U.G. & Nuclear & 04 & Urban & Male & 9 & $4^{\text {th }}$ & 66 \\
\hline 9. & N_F_5 & 40 & $12^{\text {th }}$ & Nuclear & 04 & Urban & Female & 11 & $7^{\text {th }}$ & 76 \\
\hline 10. & N_F_6 & 37 & U.G. & Nuclear & 04 & Urban & Female & 11 & $7^{\text {th }}$ & 62 \\
\hline 11. & J_M_5 & 42 & $\mathrm{Ph} . \mathrm{D}$. & Joint & 06 & Urban & Male & 11 & $7^{\text {th }}$ & 71 \\
\hline 12. & N_M_6 & 42 & Ph. D. & Nuclear & 03 & Urban & Male & 9 & $5^{\text {th }}$ & 80 \\
\hline 13. & N_F_7 & 40 & Postgraduate & Nuclear & 04 & Urban & Female & 12 & $8^{\text {th }}$ & 64 \\
\hline 14. & N_F_8 & 38 & Graduate & Nuclear & 04 & Urban & Female & 12 & $8^{\text {th }}$ & 76 \\
\hline 15. & J_M 7 & 43 & Graduate & Joint & 10 & Urban & Male & 12 & $7^{\text {th }}$ & 79 \\
\hline 16. & J_M_8 & 45 & Postgraduate & Joint & 12 & Urban & Male & 10 & $5^{\text {th }}$ & 70 \\
\hline
\end{tabular}

Note 1. A full-time mother was the primary caregiver from birth to the present.

Note 2. Joint Family comprises members of three or more generations.

Note 3. Nuclear Family comprises only parents and their children.

Note $4 . \mathrm{F}=$ Female Child, $\mathrm{J}=$ Joint Family, $\mathrm{M}=$ Male Child, $\mathrm{N}=$ Nuclear Family .

\section{Recruitment of the Participant}

There were eight researchers in the team who had a good knowledge of the qualitative research and the socio-cultural realities of the Indian society. The differences in age, experiences and academic background were minimized through a regular discussion among the researchers. Due to restrictions of a nationwide lockdown, the interviews were conducted through telephonic calls. The study was conducted during June and July, 2020. The participants were not reimbursed any compensation for their participation. The study was approved by the Ethics Committee of the University [BLINDED FOR REVIEW]. The participants belonged to the middle-class families mostly adhering to the Hindu religion.

Three inclusion criteria were adopted to choose the participants: a participant should be a full-time mother, living in either a joint family or nuclear family, and has at least one child with the age range between 9 years to 12 years. The study began only after their telephonic consent. The participants were briefed about the basic goals of the study. A purposive sampling method was used as it is appropriate when the goal is to inquire about the experiences more relevant to the phenomenon of interest (Creswell, 2014). We chose only full-time mothers since they represent an information-rich group and were able to describe and reflect upon the behaviours and experiences of their children (Patton, 2015). Guest et al. (2006) have suggested that a sample size of 12 is sufficient for qualitative study using purposive sampling. Accordingly, 16 full-time mothers were chosen through purposive sampling.

\section{Data Collection}

A semi-structured interview protocol was used to collect the data through telephonic calls. The structure of the protocol was developed as per the study goals which were identified in the beginning. The interview started with some preliminary queries about the causes and impacts of COVID-19 on human life. The mean length of the interviews was $70.14 \mathrm{~min}$ (Range $=60-81 \mathrm{~min}$ ). The questions were framed on the impacts of 
COVID-19 on life, the methods of engagement, management of emotional issues, promotion of health habits and management of the activities of the children by the joint and nuclear families during the pandemic. The contents of the interviews were audio-taped and their verbatim transcriptions were prepared.

\section{Data-Analysis}

The thematic analysis method was used to analyze data which entails organization and preparation, obtaining a general sense, coding, generating categories or themes and interpreting the data (Braun \& Clarke, 2006). Codes were assigned to each participant to ascertain confidentiality. The reliability of the coding was maintained by multiple checking and rechecking of the data and codes. The multiple reading and re-reading of the transcriptions helped to increase the familiarity of the interview contents, inherent meaning and useful insights (Barbour, 2001). A priori criteria were adopted for generating codes: the impacts of COVID-19 on life, the methods of engaging, resolving emotional issues, promoting health habits and managing the activities of the children. According to the suggestions of Guest et al. (2012), these generated codes were organized, merged and re-categorized to identifying relevant codes. Saturation was recorded after completing 12 interviews when no new themes and codes generated from further interviews consistent with the research questions (Saunders et al., 2018). Two more interviews were conducted each from joint and nuclear families to verify the saturation. An appropriate understanding of the preliminary interview protocol was developed by initial discussions among the authors.

A careful assessment and reviewing of the codes helped to incorporate the relevant modifications. The revisions of the coding framework helped to generate appropriate codes and keep out irrelevant codes. An iterative approach was employed until the complete analysis to enhance the quality of coding. A gap of two weeks was made between the initial and final scrutiny, and review of the transcriptions and codes to minimize the distortions caused by over-involvement in the data as per the suggestions of the earlier researchers (Braun \& Clarke, 2016; Guest et al., 2012). It helped to generate the final codes with a set of appropriate themes. Recurrent discussions, regular evaluation of the data, focus on the insights and meanings, consistent analysis, preparation of a codebook and attending the evidence helped to maintain the methodological integrity.

\section{Results}

Five themes were generated: negative impacts of COVID-19, differences in positive engagement, emotional protective roles, promotion of positive health habits and activity management.

\section{Theme 1: Negative impacts of COVID-19}

The uncertainties, suddenness and restrictions of lockdown had negative impacts on the lives of the children of both the families. The major negative impacts of the pandemic for the children of the joint families were disturbed life schedule, loss of happiness, extreme anxiety, altered work-life and burden due to uncertainties of COVID-19.

The experiences of boredom and disturbed lifestyle were reported by the majority of the mothers of joint and nuclear families alike.

The pandemic has made our life very boring. It has also completely disturbed our routine of life. (J_M_2)

It has affected our life in many ways. It has changed our routine and schedule of all work and made our life boring. It has also changed our food habits as my husband and children are foodie. I have to keep on cooking different items. (N_M_3)

Decreased happiness and other positive life outcomes were also commonly reported.

Our happiness has decreased. (J_F_3) 
Our self-confidence and quality of life have decreased significantly. It has confined us in a house, shaken our confidence of control and virtual house arrest. (N_M_6)

Extreme fear and anxiety were frequently described by them.

We have to take extra care of our children and in-laws. It has also given unwanted fear and anxiety. (J_F_3)

It has also developed a sense of alertness in social interactions. (J_M_3)

We frequently experience fear extreme of negative consequences, fear of infection and terror experiences. More badly, there is a strong fear of re-infection. (N_M_6)

Burden, financial loss and disturbed work-life were also reported by most of the mothers.

It has significantly affected our business. (J_M_2)

We had a business. We were selling breakfast like items. It sufficed to satisfy the need for bread and butter of more than 10 members and 2 employees. Now, we have become jobless. We are now burdened with debt. (J_M_7)

The care of family members has become a burden now. We have to engage our child without our wish. It causes the loss of work and makes us frustrated. (N_M_6)

Loss of study of children was another negative consequence of the pandemic.

Students are facing great loss in their studies. They are not paying that much attention like in class. (J_F_2)

It has disturbed the study of children. (J_F_3)

\section{Theme 2: Differences in positive engagement}

Engagements in online classes, games, watching television (TV) and playing with mobile, household works, playing with the elders and siblings, listening stories from grandparents, studies in the supervision of grandparents and creative activities such as drawing, painting or sketching were the methods of engagement of children in the joint families.

Most of them reported that their children have to regularly attend online classes.

They are busy taking their online classes and doing homework or assignments. Children are almost busy in playing online games on phone or watching TV but we restrict watching excessive TV or using mobiles as theses may harm their eyes. (J_M_2)

Instead of letting them watch unnecessary TV and mobiles, we engage them in helping us in household works. (J_F_2)

Playing with family members and involvement in some positive behaviours were another method of engagement in joint families.

They are very happy about playing with siblings or cousins and grandparents. (J_M_2)

When they are free they also play Ludo or crack jokes with their grandparents. Sometimes, they listen to stories from them and they get help in the study. (J_F_2)

Children of the joint families were also engaged in some household tasks.

They do small household tasks such as dusting, watering plants and helping in the kitchen especially when the maid is on leave. They also help us in serving foods to their grandparents. (J_F_2)

Sometimes they help their father and uncles in outdoor activities. (J_M_3)

They also help their grandmother in giving food, water and medicines. (J_F_3) 
Joint families also engaged their children in some creative tasks and activities.

We also engage our children in learning drawing, painting or sketches through which they can learn something new. (J_F_3)

They are also learning new skills including growing vegetables and learning to cook meals. (J_M_3)

They also spend time with their grandparents by gossiping. (J_M_5)

Nuclear families differed significantly in their methods of engagements of their children during the pandemic. Most of them reported that the online class was one compulsory engagement. It was almost similar to the children of joint families. One departure was reported in more reliance on the children of these families on TV, mobiles and indoor games. Besides, sleeping and lesser engagement in creative activities of drawing and paintings were also reported by the mothers of nuclear families.

After their classes, they get busy watching TV or playing games in the mobile phone. (N_M_1)

Along with watching TV, they also play games on mobiles or indoor games with their siblings and us. (N_F_1)

After lunch, they sleep for at least one hour regularly and play with us or alone in the evening. (N_M_6)

Sometimes, we engage them in drawing and colouring pictures and paintings. (N_M_4)

\section{Theme 3: Differences in emotional protective roles}

Enhanced care, close supervision by the elders, support and positive engagement in play, health and other activities were the methods through which the emotional support was extended to the children in the joint families.

We tell them to wash their hands regularly and frequently with soaps or hand wash. They have understood now that they have to be very careful during this time. (J_M_2)

We manage the emotional issues of our children by telling not to be afraid in this situation. We motivate them to take care of personal hygiene such as using a mask, washing hands or sanitizing them several times. $\left(\mathrm{J}_{-} \mathrm{F}_{-} 2\right)$

They also get emotional support from grandparents or elders and because of this support they don't get panic. (J_M_2)

Due to the emotional support of our joint family, we feel protected. (J_F_2)

My children are always engaged with their grandparents and other family members so there hardly arise any emotional issues. (J_M_5)

We motivate them to focus on their studies and to learn new things. (J_M_3)

The nuclear families significantly differed in managing the emotional problems of their children. They promoted more engagement of their children through indoor games, TV and mobile and irregular activities and thus, could provide limited emotional support to their children.

We motivate them for frequent hand wash and sanitize their hands and not to touch anything unnecessarily. (N_F_5)

We play indoor games with them such as ludo, chess and carom to engage them. (N_F_6)

We engage him in activities such as TV, games and mobile games. (N_M_6)

Sometimes, the parents from the nuclear families reported it difficult to manage the feelings of their children. 
He is younger and it is very difficult for us to manage and engage him. He reports negative feelings of boredom. He is younger so makes the situation worse. Sometimes, he does irregular activities. (N_M_6)

They show rigidity and boredom. We make them fear that if they go outside they will become ill. (N_F_7)

\section{Theme 4: Differences in the promotion of positive health habits}

Healthy diets, exercise, games and sports, protective habits and use of some Ayurvedic medicines were the means through which health of the children in joint families was promoted.

I try to take care of the health of our all members including children and older persons of our house. We include fresh vegetables in our meals. Fruits such as apple, orange and banana are among our daily needs. Children are served sometimes fruit chat and juices. Taking milk before going to sleep is compulsory for especially children and elders of our family. (J_M_2)

We also try to keep them physically active in engaging them with doing physical exercise and play games. We also ask them to do yoga exercises. (J_F_4)

We also use medicine for boosting immunity. We also take steam occasionally. (J_F_2)

We have adopted Ayurvedic formulations nowadays. We use ginger and garlic while cooking foods for better immunity. (J_M_5)

Apart from some similarities such as healthy diets, exercise etc. in the promotion of positive health of their children, the nuclear families imposed more restrictions on outdoor games with friends and permitted their children only to practice Yoga, play indoor games and observe restrictions during the pandemic.

I make him practice yoga in the morning. He practices Anulom-Vilom (a yogic exercise). We have to play with him. We involve him in games regularly. (N_M_6)

We do not allow our children to play outside and to avoid playing with their friends and neighbourhood children. It is safe and secure. N_M_4

\section{Theme 5: Differences in activity management}

Restrictions on the excessive TV watching, mobile play and more emphasis on the involvement in household tasks, team play, storytelling and creative activities were the means through which the activities of children in joint families were managed.

We tell them to watch TV or play with mobiles too much. (J_M_2)

We have restricted and limited the time for watching TV. (J_F_3)

We also engage them in doing little household things so that they can be physically active and learn managing household items. (J_F_4)

Children also play Ludo in free time or sometimes they gossip with their siblings, cousins and grandmother. (J_M_3)

In the evening, our children assemble in front of their grandparents and listen to stories. (J_F_3)

We also engage them in paintings, make craft art and practice dance. (J_F_2)

We also manage their activities by involving them in teaching the traditional family cultures and rituals. (J_F_4)

They also spend time with their grandparents in the morning or evening walks. (J_M_5) 
The mothers of nuclear families relied more on some restrictive methods to manage the activities of their children. For instance, allowing TV watching or playing with mobiles, in-door creative activities, playing indoor games and household activities were chief methods.

We manage his activities by allowing him to watch his favourite TV serials, cartoons or recipes of cooking. (N_M_4)

We also engage them in doing the things of their choice or hobby such as painting works, art and craftworks. (N_F_5)

We also tell them moral stories and cracking jokes. (N_F_6)

We motivate to involve them in playing indoor games such as ludo, carom or chess on phone. (N_F_1) (N_M_4)

We also manage his activities by playing with him or gossiping or discussing something related to his study or about his friends. (N_M_1)

Sometimes, we also engage them in doing little household things. (N_M_4)

\section{Discussion}

The findings of the study proved the contention that the perceived consequences of COVID-19 were equally distressful to both the mothers of the joint and nuclear families for their children. There were significant differences in the way the two families managed their perceived threats to life, well-being and overall existence caused by the pandemic. It appears that joint families provide for a broader temporal dimension, experiential resources and buffer mechanisms for moderating the negative consequences of the pandemic as compared to the nuclear families. The presence of larger members in the joint families provides for a positive and dependable source of social stimulation, larger experience base, care, positive stories of life, control mechanisms and sources of interpretation which eased protection of their children. A joint family in India is a strength which may bear the negative consequences of modernity. Conversely, the nuclear families may have been gripped by over-alertness and lack of human resources to deal with the flow of negative attributions and emotions arising out of the uncertainties of the pandemic.

A joint family in India has been suggested to be the chief vehicle of collective values comprising interdependence, mutuality, a collective self and community-orientation (Choi \& So, 2019; Tiwari, Kashyap, et al., 2020). Contrarily, a nuclear family is born out of the influence of postmodern lifestyle, the proliferation of materialistic and individualistic values, achievement-orientation, and a search for better opportunities for education and employment. The two value systems may cultivate two distinct modes of relationships, care and the life goals which may have characteristically different impacts on the various life outcomes of their children. The joint families were reported to carry more resources to engage positively their children in creativity, studies, exercise and entertainment as compared to the nuclear families. Likewise, the joint families appeared to resolve easily the emotional grievances, promote positive emotional engagement and support emotionally as compared to the nuclear families. Significant differences were observed in their attending the food habits, health grievances and physical exercise of children. The joint families played more positive roles in managing play behaviours, health habits, use of mass media and other activities of children than nuclear families. Thus, the diversity in the patterns of moral, emotional, interpersonal, temporal and other resources may have made a significant difference in the experiences of good and bad times faced by children of joint and nuclear families. Besides, these resources may have led dissimilar experiences of satisfaction, care, play, belongingness, learning, creativity, positive involvement, support, discipline, morality and emotion regulation for children of the two families.

It was noticeable that the current pandemic equally had negative impacts on the members of the joint and nuclear families (Theme 1). The mothers of both the families reported almost similar perceived negative 
consequences. The uncertain, novel and fatal nature of the pandemic give birth to a set of epidemic-like psycho-social processes which may spread at a faster pace in a variety of forms to individuals and collectives (Strong, 1990). This psycho-social epidemic is characterized by fear, explanation and moralization, and the epidemic of action which may be even more severe in the face of poor knowledge (Strong, 1990). This psycho-social epidemic may carry suspicion, insecurity, irrationality, misinformation, panic, stigmatization, avoidance, segregation, abuse and theories of the origin of disease and its effects and metaphysical explanations among educated as well as illiterate people (Tiwari, Rai, et al., 2020; Weber \& Goldmeier, 1983).

According to Illness Perceptions Theory (Leventhal et al., 1998), the stressful situations involve representations, coping responses and appraisal of coping outcomes. The stress may be perceived more severe if the identity, cause, timeline, consequences and curability representations do not match with the current normative guidelines of the known epidemics (Leventhal et al., 1998). The current pandemic may have lowered the self-efficacy of the participants which refers to a person's beliefs in his/her abilities to accomplish a task in a given situation according to some accepted criteria (Bandura, 1977). It may be argued that the current pandemic may have lowered the self-efficacy and culminated in their perceived psychological distress (de Zwart et al., 2009). The restrictions of the pandemic have reduced social interaction. Being human, all individuals carry a strong need for interactions to make sense of their world, to get satisfaction and happiness, and to live well (J. Sun et al., 2019). Due to the lack of similar past experiences, the loss of social connection may have caused them to perceive stress. Similar to the findings of the present study, many earlier researchers have reported negative psychological consequences to be linked with the current pandemic. For example, COVID-19 has been found to cause confusion, stress, anxiety, restrictions, fear of infection, frustration, boredom, loss and stigma (Brooks et al., 2020; Racine et al., 2020), disturbance in the emotional attachment (Jiao et al., 2020) and lowered well-being among children and adults (Avenue et al., 2020; Ghosh et al., 2020; Lee, 2020).

Differences in positive engagement, emotional protective roles, promotion of positive health habits and activity management of the joint and nuclear families have been found (Themes 2, 3, 4 \& 5). Along with some similarities, the two families differed significantly in the way they engaged their children during the pandemic. The joint families were reported to engage their children through play with elders and siblings, storytelling by grandparents and creative activities while the nuclear families heavily relied on the use of television, mobile and indoor games. These differences in positive engagement methods of the two families may be due to the differences in the available resources in the form of elders, multiple relationships and temporal dimensions. It has been argued that the joint families provide for more alternatives for interactions, play and creative activities for children (Bisht \& Sinha, 1981).

The elders have long and rich experiences of life, positive stories, wisdom, emotional maturity and forgiveness (Ghaemmaghami et al., 2011; Hayward \& Krause, 2013) and carry more agreeableness and lesser neuroticism (Steiner et al., 2012). Elders may also carry generativity which involves finding meaningful work and contributing to the development of others through activities such as volunteering, mentoring and raising children (Erikson \& Erikson, 1997). These resources in the form of elders in the joint families may have supported them to exercise more positive engagements of their children than the nuclear families. For the parents of nuclear families, dealing with the restrictions of the pandemic particularly may be more stressful who have to make a balance among their personal life, work, raising children and loneliness (Spinelli et al., 2020). These challenges may have reduced the psychological resources in the hands of the parents of nuclear families to engage and protect their children more positively.

\section{Summary and Implications}

The joint and nuclear families showed dissimilar resources and mechanisms for dealing with the issues of their children during the restrictions of COVID-19. The joint families evinced a set of robust positive resources, mechanisms, temporal dimensions, relational resources, knowledge and relevant support to deal 
with the task of engaging their children. Conversely, the nuclear families showed dissimilar resources and mechanisms which were characterized by slight restrictions, over-alertness, lack of broader experiences and socio-emotional repertoire. Moreover, the joint family is said to carry collective values which reflect more support, cooperation, care, interdependence, discipline, cultural knowledge and conflict resolution mechanisms. Conversely, a nuclear family carries individualistic values which catalyze independence, narrow temporal dimension, individualism, achievement-orientation, limited support and cooperation and independent selfconstrual. The differences in these resources and mechanisms may be argued to surface in their dissimilar abilities to protect and engage their children during the current pandemic.

The findings showed that living in a joint family is beneficial and protective for both individuals and society. Further explorations are needed to understand the positive mechanisms of different types of families. This will help to understand policymakers, practitioners and researchers to chart out appropriate and effective intervention plans and policies to cater to the needs of the different types of family systems prevailing in different societies. The assessment of the impacts of the current pandemic may be carried out in terms of different family structures, groups and collectives which will help develop insights to understand their moderating impacts. This understanding may help to provide better resources for the positive development of individuals and groups.

\section{References}

Ahirwar, G., Tiwari, G. K., \& Rai, P. K. (2019). Exploring the nature, attributes and consequences of forgiveness in children: A qualitative study. Psychological Thought, 12(2), 214-231. https://doi.org/10.5964/psyct.v12i2.347

Avenue, H. R. W. | 350 F., York, 34th Floor | New, \& t 1.212.290.4700, N. 10118-3299 U. |. (2020, April 9). COVID-19's Devastating Impact on Children. Human Rights Watch. https://www.hrw.org/news/2020/04/09/covid-19s-devastating-impact-children

Bandura, A. (1977). Self-efficacy: Toward a unifying theory of behavioral change. Psychological Review, 84(2), 191-215. https://doi.org/10.1037/0033-295X.84.2.191

Barbour, R. S. (2001). Checklists for improving rigour in qualitative research: A case of the tail wagging the dog? BMJ, 322(7294), 1115-1117. https://doi.org/10.1136/bmj.322.7294.1115

Bernardi, F., Härkönen, J., Boertien, D., Rydell, A., Bastaits, K., \& Mortelmans, D. (2013). Effects of family forms and dynamics on children's well-being and life chances: Literature review. Undefined. /paper/Effects-of-family-forms-and-dynamics-on-children\%27s-BernardiH\%C3\%A4rk\%C3\%B6nen/09aad957d844df88bc9672fff8f2e30ab1b9908c

Bisht, S., \& Sinha, D. (1981). Socialization, family, and psychological differentiation. In D. Sinha, Socialization of the Indian Child (pp. 41-54). Concept Publishing Co.

Braun, V., \& Clarke, V. (2006). Using thematic analysis in psychology. Qualitative Research in Psychology, 3(2), 77-101. https://doi.org/10.1191/1478088706qp063oa

Braun, V., \& Clarke, V. (2016). (Mis)conceptualising themes, thematic analysis, and other problems with Fugard and Potts' (2015) sample-size tool for thematic analysis. International Journal of Social Research Methodology, 19(6), 739-743. https://doi.org/10.1080/13645579.2016.1195588

Brooks, S. K., Webster, R. K., Smith, L. E., Woodland, L., Wessely, S., Greenberg, N., \& Rubin, G. J. (2020). The psychological impact of quarantine and how to reduce it: Rapid review of the evidence. The Lancet, 395(10227), 912-920. https://doi.org/10.1016/S0140-6736(20)30460-8 
Cai, H., Sedikides, C., \& Jiang, L. (2013). Familial Self as a Potent Source of Affirmation: Evidence From China. Social Psychological and Personality Science, 4(5), 529-537. https://doi.org/10.1177/1948550612469039

Choi, J., \& So, J. (2019). Effects of self-affirmation on message persuasiveness: A cross-cultural study of the U.S. and South Korea. Asian Journal of Communication, 29(2), 128-148. https://doi.org/10.1080/01292986.2018.1555265

Creswell, J. W. (2014). Research design: Qualitative, quantitative, and mixed methods approaches (4th ed). SAGE Publications.

de Zwart, O., Veldhuijzen, I. K., Elam, G., Aro, A. R., Abraham, T., Bishop, G. D., Voeten, H. A. C. M., Richardus, J. H., \& Brug, J. (2009). Perceived Threat, Risk Perception, and Efficacy Beliefs Related to SARS and Other (Emerging) Infectious Diseases: Results of an International Survey. International Journal of Behavioral Medicine, 16(1), 30-40. https://doi.org/10.1007/s12529-008-9008-2

Erikson, E. H., \& Erikson, J. M. (1997). The life cycle completed (Extended version). W.W. Norton.

Fomby, P., \& Cherlin, A. J. (2007). Family Instability and Child Well-Being. American Sociological Review, 72 (2), 181-204. https://doi.org/10.1177/000312240707200203

Gaines, S. O., Marelich, W. D., Bledsoe, K. L., Steers, W. N., Henderson, M. C., Granrose, C. S., Barájas, L., Hicks, D., Lyde, M., Takahashi, Y., Yum, N., Ríos, D. I., García, B. F., Farris, K. R., \& Page, M. S. (1997). Links between race/ethnicity and cultural values as mediated by racial/ethnic identity and moderated by gender. Journal of Personality and Social Psychology, 72(6), 1460-1476. https://doi.org/10.1037/00223514.72.6.1460

Galea, S., Merchant, R. M., \& Lurie, N. (2020). The Mental Health Consequences of COVID-19 and Physical Distancing: The Need for Prevention and Early Intervention. JAMA Internal Medicine. https://doi.org/10.1001/jamainternmed.2020.1562

Ghaemmaghami, P., Allemand, M., \& Martin, M. (2011). Forgiveness in Younger, Middle-Aged and Older Adults: Age and Gender Matters. Journal of Adult Development, 18(4), 192-203. https://doi.org/10.1007/s10804-011-9127-x

Ghosh, R., Dubey, M. J., Chatterjee, S., \& Dubey, S. (2020). Impact of COVID -19 on children: Special focus on the psychosocial aspect. Minerva Pediatrica, 72 (3). https://doi.org/10.23736/S0026-4946.20.05887-9

Guest, G., Bunce, A., \& Johnson, L. (2006). How Many Interviews Are Enough?: An Experiment with Data Saturation and Variability. Field Methods, 18(1), 59-82. https://doi.org/10.1177/1525822X05279903

Guest, G., MacQueen, K. M., \& Namey, E. E. (2012). Applied thematic analysis. Sage Publications.

Gul, N., Ghani, N., Alvi, S. M., Kazmi, F., \& Shah, A. A. (2017). Family system's role in the psychological well-being of the children. Khyber Medical University Journal, 9(1), 29-32.

Gupta, M., \& Sukamto, K. (2020). Cultural Communicative Styles: The Case of India and Indonesia. International Journal of Society, Culture $\&$ Language, 0, 1-16.

Hayward, R. D., \& Krause, N. (2013). Trajectories of change in dimensions of forgiveness among older adults and their association with religious commitment. Mental Health, Religion $\&$ Culture, 16(6). https://doi.org/10.1080/13674676.2012.712955

Hoshino-Browne, E., Zanna, A. S., Spencer, S. J., Zanna, M. P., Kitayama, S., \& Lackenbauer, S. (2005). On the cultural guises of cognitive dissonance: The case of Easterners and Westerners. Journal of Personality and Social Psychology, 89(3), 294-310. https://doi.org/10.1037/0022-3514.89.3.294

Jiao, W. Y., Wang, L. N., Liu, J., Fang, S. F., Jiao, F. Y., Pettoello-Mantovani, M., \& Somekh, E. (2020). Behavioral and Emotional Disorders in Children during the COVID-19 Epidemic. The Journal of Pediatrics, S002234762030336X. https://doi.org/10.1016/j.jpeds.2020.03.013 
Kauts, A., \& Kaur, B. (2016). A study of children's behaviour in relation to family environment and technological exposure at pre primary stage. MIER Journal of Educational Studies, Trends and Practices, 1(2), Article 2. http://www.mierjs.in/ojs/index.php/mjestp/article/view/12

Klein, T. P., Devoe, E. R., Miranda-Julian, C., \& Linas, K. (2009). Young children's responses to September 11th: The New York City experience. Infant Mental Health Journal, 30(1), 1-22. https://doi.org/10.1002/imhj.20200

Kondiba, B. V., \& Hari, K. S. (2018). Emotional maturity among joint family and nuclear family children. The International Journal of Indian Psychology, 6(2), 109-112. https://doi.org/10.25215/0602.217

Kreppner, K. (2013). Family Systems and Life-span Development (1st ed.). Psychology Press. https://doi.org/10.4324/9780203771280

Lee, J. (2020). Mental health effects of school closures during COVID-19. The Lancet Child 83 Adolescent Health, S2352464220301097. https://doi.org/10.1016/S2352-4642(20)30109-7

Leventhal, H., Leventhal, E. A., \& Contrada, R. J. (1998). Self-regulation, health, and behavior: A perceptualcognitive approach. Psychology \& Health, 13(4), 717-733. https://doi.org/10.1080/08870449808407425

Levitt, H. M., Bamberg, M., Creswell, J. W., Frost, D. M., Josselson, R., \& Suárez-Orozco, C. (2018). Journal article reporting standards for qualitative primary, qualitative meta-analytic, and mixed methods research in psychology: The APA Publications and Communications Board task force report. American Psychologist, 73(1), 26-46. https://doi.org/10.1037/amp0000151

Levitt, H. M., Motulsky, S. L., Wertz, F. J., Morrow, S. L., \& Ponterotto, J. G. (2017). Recommendations for designing and reviewing qualitative research in psychology: Promoting methodological integrity. Qualitative Psychology, 4(1), 2-22. https://doi.org/10.1037/qup0000082

Mackay, R. (2005). The Impact of Family Structure and Family Change on Child Outcomes: A Personal Reading of the Research Literature.

Markus, H. R., \& Kitayama, S. (1991). Culture and the self: Implications for cognition, emotion, and motivation. Psychological Review, 98(2), 224-253. https://doi.org/10.1037/0033-295X.98.2.224

Merriam-Webster Dictionary. (2020a). Definition of Joint family. https://www.merriamwebster.com/dictionary/joint+family

Merriam-Webster Dictionary. (2020b). Definition of nuclear family. https://www.merriamwebster.com/dictionary/nuclear+family

Patton, M. Q. (2015). Qualitative research \& evaluation methods: Integrating theory and practice (Fourth edition). SAGE Publications, Inc.

Racine, N., Cooke, J. E., Eirich, R., Korczak, D. J., McArthur, B., \& Madigan, S. (2020). Child and adolescent mental illness during COVID-19: A rapid review. Psychiatry Research, 292, 113307. https://doi.org/10.1016/j.psychres.2020.113307

Saunders, B., Sim, J., Kingstone, T., Baker, S., Waterfield, J., Bartlam, B., Burroughs, H., \& Jinks, C. (2018). Saturation in qualitative research: Exploring its conceptualization and operationalization. Quality $\mathcal{E}$ Quantity, 52(4), 1893-1907. https://doi.org/10.1007/s11135-017-0574-8

Scabini, E., \& Manzi, C. (2010). Identity in family processes. In S. J. Schwartz, K. Luyckx, \& V. L. Vignoles, Handbook of identity theory and research (pp. 565-584). Springer.

Spinelli, M., Lionetti, F., Pastore, M., \& Fasolo, M. (2020). Parents' Stress and Children's Psychological Problems in Families Facing the COVID-19 Outbreak in Italy. Frontiers in Psychology, 11, 1713. https://doi.org/10.3389/fpsyg.2020.01713 
Steiner, M., Allemand, M., \& McCullough, M. E. (2012). Do agreeableness and neuroticism explain age differences in the tendency to forgive others? Personality \& Social Psychology Bulletin, 38(4), 441-453. https://doi.org/10.1177/0146167211427923

Strong, P. (1990). Epidemic psychology: A model. Sociology of Health and Illness, 12(3), 249-259. https://doi.org/10.1111/1467-9566.ep11347150

Sun, J., Harris, K., \& Vazire, S. (2019). Is well-being associated with the quantity and quality of social interactions? Journal of Personality and Social Psychology. https://doi.org/10.1037/pspp0000272

Sun, Y., \& Li, Y. (2002). Children's Well-Being during Parents' Marital Disruption Process: A Pooled Time-Series Analysis. Journal of Marriage and Family, 64(2), 472-488. https://doi.org/10.1111/j.17413737.2002.00472.x

Tiwari, G. K., Kashyap, A. K., Rai, P. K., Tiwari, R. P., \& Pandey, R. (2020). The Collective-affirmation in Action: Understanding the Success of Lockdown in India after the Outbreak of COVID-19 [Preprint]. Preprints. https://doi.org/10.22541/au.158949202.27402247

Tiwari, G. K., Pandey, R., \& Rai, P. K. (2020). Independent and Interdependent Self-affirmations in Action: Understanding their dynamics in India during COVID-19. https://doi.org/10.17605/OSF.IO/HW3CU

Tiwari, G. K., Rai, P. K., Dwivedi, A., \& Ray, B. (2020). The Outbreak of COVID-19: A Narrative Thematic Analysis of the Perceived Psychological distress and health Outcomes [Preprint]. Preprints. https://doi.org/10.22541/au.158955320.05988992

Tiwari, G. K., Singh, A. K., Parihar, P., Pandey, R., Sharma, D. N., \& Rai, P. K. (2020). Understanding the perceived health outcomes of children during COVID-19 pandemic [Preprint]. Preprints. https://doi.org/10.22541/au.158958012.27449923

United Nations Organization. (2020). Policy Brief: The Impact of COVID-19 on children (pp. 1-17).

Wang, G., Zhang, Y., Zhao, J., Zhang, J., \& Jiang, F. (2020). Mitigate the effects of home confinement on children during the COVID-19 outbreak. The Lancet, 395(10228), 945-947. https://doi.org/10.1016/S01406736(20)30547-X

Weber, J., \& Goldmeier, D. (1983). Medicine and the Media. British Medical Journal, 287(6389), 420-420. https://doi.org/10.1136/bmj.287.6389.420

World Health Organization. (2020). Coronavirus disease 2019 (COVID-19) Situation Report-193. https://www.who.int/docs/default-source/coronaviruse/situation-reports/20200731-covid-19-sitrep193.pdf?sfvrsn=42a0221d_2 